\title{
Synthesis of ZnO Nanowires and Their Photovoltaic Application: ZnO Nanowires/AgGaSe 2 Thin Film Core-Shell Solar Cell
}

\author{
Elif Peksu and Hakan Karaagac \\ Department of physics, Istanbul Technical University, Maslak, 34469 Istanbul, Turkey \\ Correspondence should be addressed to Hakan Karaagac; karaagacha@itu.edu.tr
}

Received 1 September 2015; Revised 4 November 2015; Accepted 8 November 2015

Academic Editor: Thierry Baron

Copyright (C) 2015 E. Peksu and H. Karaagac. This is an open access article distributed under the Creative Commons Attribution License, which permits unrestricted use, distribution, and reproduction in any medium, provided the original work is properly cited.

In this investigation, hydrothermal technique was employed for the synthesis of well-aligned dense arrays of $\mathrm{ZnO}$ nanowires (NWs) on a wide range of substrates including silicon, soda-lime glass (SLG), indium tin oxide, and polyethylene terephthalate (PET). Results showed that $\mathrm{ZnO}$ NWs can be successfully grown on any substrate that can withstand the growth temperature $\left(\sim 90^{\circ} \mathrm{C}\right)$ and precursor solution chemicals. Results also revealed that there was a strong impact of growth time and $\mathrm{ZnO}$ seed layer deposition route on the orientation, density, diameter, and uniformity of the synthesized nanowires. A core-shell n-ZnO NWs/p$\mathrm{AgGaSe}_{2}$ (AGS) thin film solar cell was fabricated as a device application of synthesized $\mathrm{ZnO}$ nanowires by decoration of nanowires with $\sim 700 \mathrm{~nm}$ thick sputtering deposited AGS thin film layer, which demonstrated an energy conversion efficiency of $1.74 \%$ under $100 \mathrm{~mW} / \mathrm{cm}^{2}$ of simulated solar illumination.

\section{Introduction}

In recent years, there has been an increasing amount of literature on both one-dimensional nanostructures synthesis and employment of a wide range of thin film semiconductor materials for the realization of high-efficiency, low-cost solar cells. However, there are a quite few research studies on combining these efforts. In this regard, employing onedimensional (1D) nanostructures such as nanowires (NWs), nanorods (NRs), and nanotubes (NTs) to construct threedimensional (3D) device architectures is a very promising approach for the realization of next-generation highefficiency solar cells at lower cost $[1,2]$.

In the past two decades, to improve the performance of solar cells, 3D photovoltaic device architectures including axial architecture, radial architecture (core-shell), and nanostructures embedded in thin film models have been studied extensively with different material combinations [2]. In particular, core-shell architecture offers significant advantages over its planer counterparts due to its unique properties, such as light trapping, efficient charge collection, quantum confinement, and decoupling the photon absorption and carrier collection in an effective way. Currently, silicon $(\mathrm{Si})$, titanium dioxide $\left(\mathrm{TiO}_{2}\right)$, and zinc oxide $(\mathrm{ZnO})$ are the most commonly employed semiconductor materials for the construction of core-shell solar cells as the core component. There are many potential reasons to choose these materials such as their abundance in the earth crust, nontoxic nature, convenient bandgap nature/energy value, stability, and outstanding chemical/physical and optical properties [3]. In core-shell structure, the shell component plays a crucial role in determining the performance of the designed device [4-6]. As a shell component, chalcopyrite semiconductors $\left(\mathrm{CuInSe}_{2}, \mathrm{Cu}(\mathrm{In}, \mathrm{Ga})(\mathrm{S}, \mathrm{Se})_{2}\right.$, and $\left.\mathrm{Ag}(\mathrm{In}, \mathrm{Ga})(\mathrm{S}, \mathrm{Se})_{2}\right)$ are regarded as promising candidates due to their convenient bandgap nature and energy value, which exactly matches the most abundant part of solar spectrum reaching the surface of the earth $[7,8]$. Therefore, the proper bandgap nature/energy value of these materials suggests that more than $90 \%$ of the incident light can be absorbed in a few micrometers of the material [9]. Chalcopyrites along with $\mathrm{CdTe}$ are regarded as the most promising semiconductors alternatives to $\mathrm{Si}$ and are at the heart of today's thin film based solar cells [10].

In the present investigation, we have constructed 3D coreshell solar cell by employing a sputtered $\mathrm{AgGaSe}_{2}$ (AGS) thin film as shell component due to its high absorption coefficient 
$\left(\sim 10^{5} \mathrm{~cm}^{-1}\right)$ and convenient bandgap nature/energy (direct bandgap with $\sim 1.8 \mathrm{eV}$ ). It is a well-known fact that AGS semiconductors can also be used for many other applications including frequency doubling $\left(\mathrm{CO}_{2}\right.$ laser output) and photodetectors [11-15]. For the core component of the fabricated solar cell, $\mathrm{ZnO}$ material was preferred, a semiconductor with a large bandgap $(3.37 \mathrm{eV})$ and exciton binding energy $(60 \mathrm{meV})$ at room temperature, due to its many outstanding properties such as the piezoelectricity, near band emission, and transparent conductivity. $\mathrm{ZnO}$ has been widely used for many optoelectronic devices so far, including solar cells, light-emitting diodes (LEDs), and gas sensing [3, 16-18].

A wide range of fabrication techniques have been reported in literature so far for the synthesis of $1 \mathrm{D}$ nanostructures, which can be classified into different routes: (i) vapor and (ii) solution based techniques [19-21]. Of several solution based approaches, hydrothermal technique is of a special interest due to its many advantages such as low growth temperature, ease of controllable doping, reliable and contamination-free growth, tunable physical parameters, allowing mass production, and no requirement of vacuum and expensive equipment [22]. Based on these considerations, therefore, in the present study, $\mathrm{ZnO}$ NWs were synthesized using hydrothermal technique.

The object of this study is to synthesize $\mathrm{ZnO}$ nanowires (NWs) by hydrothermal technique and then incorporate them into $\mathrm{AgGaSe}_{2}$ chalcopyrite thin film to fabricate a coreshell structured solar cell. As n-ZnO NW/p-AgGaSe $e_{2}$ coreshell type heterojunctions have not been studied so far, it is going to be the first study reporting solar cell parameters of the device associated with these material combinations.

\section{Experimental}

$\mathrm{ZnO} \mathrm{NWs}$ were grown onto different substrates including soda-lime glass (SLG) precoated with indium thin oxide (ITO), SLG, PET (polyethylene terephthalate), and n-Si wafer substrates $((100)$ orientation and $1-10(\Omega \cdot \mathrm{cm})$ resistivity) using hydrothermal growth technique. For the synthesis of $\mathrm{ZnO}$ NWs, $\sim 30 \mathrm{~nm}$ thick $\mathrm{ZnO}$ seed layers were deposited onto the aforementioned substrates by using both sputtering and sol-gel techniques. Sputter-deposited seed layers were deposited using a radiofrequency (RF) magnetron system, the employed power of which was $150 \mathrm{~W}$ under $5 \times 10^{-3}$ Torr in $\mathrm{Ar}$ atmosphere. For the fabrication of $\mathrm{ZnO}$ seed layers by sol-gel route, a $\mathrm{ZnO}$ precursor solution was prepared by dissolving zinc acetate dihydrate [ $\mathrm{ZnAc}: \mathrm{Zn}\left(\mathrm{COOCH}_{3}\right)_{2} \cdot 2 \mathrm{H}_{2} \mathrm{O}$ ] in 2-propanol and diethanolamine (DEA, $\mathrm{C}_{4} \mathrm{H}_{11} \mathrm{NO}_{2}$ ), assigned as solute, solvent, and chelating agent, respectively. The molar ratios of DEA/ZnAc and $\mathrm{H}_{2} \mathrm{O} / \mathrm{ZnAc}$ were chosen as 1 and $1 / 2$, respectively, to prepare a solution with $0.4 \mathrm{M}$ concentration, details of which have been given elsewhere $[17,23]$. The precursor solution was stirred at $70^{\circ} \mathrm{C}$ for $1 \mathrm{~h}$ to get a clear and homogenous solution. After that, $\mathrm{ZnO}$ seed layers were deposited on precleaned SLG substrates by spin coating at one step with spinning speed of 5000 revolutions per minute $(\mathrm{rpm})$ for $1 \mathrm{~min}$. The spin coating process was based on a single stage coating process to obtain $\sim 30 \mathrm{~nm}$ thick $\mathrm{ZnO}$ seed layer. Spin-coated seed layers were first preheated at $300^{\circ} \mathrm{C}$ on hot plate for $10 \mathrm{~min}$ and then annealed at $550^{\circ} \mathrm{C}$ for $1 \mathrm{~h}$ in ambient air for the complete crystallization of seed layer and evaporation of the remained organics in the thin film structure. Following the deposition of the $\mathrm{ZnO}$ seed layer, the substrates were subjected to a solution based on equimolar $25 \mathrm{mM}\left(\mathrm{Zn}\left(\mathrm{NO}_{3}\right)_{2}\right) \cdot 6 \mathrm{H}_{2} \mathrm{O}$ (zinc nitrate hexahydrate, Sigma-Aldrich) and HMTA (hexamethylenetetramine, Sigma-Aldrich) as precursors in deionized (DI) water (with $18 \mathrm{M} \Omega \cdot \mathrm{cm}$ resistivity). During the synthesis of $\mathrm{ZnO}$ nanowires, the solution temperature and the growth time were set to $90^{\circ} \mathrm{C}$ and 1.5-3 hours, respectively [16].

For the fabrication of $\mathrm{n}-\mathrm{ZnO} \mathrm{NWs} / \mathrm{p}-\mathrm{AgGaSe}_{2}$ core-shell solar cell, ZnO NWs grown on SLG substrate (precoated with ITO) were decorated with $\mathrm{AgGaSe}_{2}$ (AGS) thin films. For the deposition of AGS thin films, a three-source sputtering system (Vaksis) was preferred. Four-inch $\mathrm{Ag}$ and $\mathrm{GaSe}$ sputtering targets (at a tilt angle of $30^{\circ}$ ) were used as sources for the sequential deposition of $\mathrm{Ag}$ and $\mathrm{GaSe}$ thin film layers. For the plasma generation in the chamber, argon gas with $99.99 \%$ purity was employed, which was set to $6 \mathrm{sccm}$ during the film deposition. The distance between targets and the substrate during the deposition cycle was around $25 \mathrm{~cm}$. To enhance the uniformity of AGS thin films, the substrate was rotated on a heated plate during deposition process. As it is semi-insulating material, for the deposition of GaSe thin film RF sputtering was used with power of $75 \mathrm{~W}$ under $5 \times 10^{-3}$ Torr Ar gas pressure. The deposition of $\mathrm{Ag}$ thin film layers was carried out by DC magnetron sputtering with a $20 \mathrm{~W}$ power in a $5 \times 10^{-3}$ Torr Ar gas pressure atmosphere. The deposition rates for the sequentially deposited Ag and GaSe layers were chosen as $1 \AA / s$ and $2 \AA / s$, respectively. Prior to decoration of $\mathrm{ZnO}$ NWs with AGS, to optimize the quality of AGS thin films, single layers of $\mathrm{Ag}$ and GaSe were sequentially deposited on SLG substrates to form $\mathrm{GaSe} / \mathrm{Ag} / \mathrm{GaSe} / \mathrm{Ag} / \mathrm{GaSe} / \mathrm{Ag} / \mathrm{GaSe} / \mathrm{Ag} / \mathrm{GaSe}$ multilayers. During the optimization cycle the substrate temperature remained constant at $150^{\circ} \mathrm{C}$ and the thickness of $\mathrm{Ag}$ and GaSe layers was set to $20 \mathrm{~nm}$ and $125 \mathrm{~nm}$, respectively. Both deposition rate and thickness of each layer were simultaneously monitored with integrated oscillatory quartz (Inficon $\mathrm{XTM} / 2$ ). Following the sequential deposition of $\mathrm{Ag}$ and GaSe layers, they were annealed in vacuum at temperature of $275^{\circ} \mathrm{C}$ for $30 \mathrm{~min}$ to trigger the interdiffusion of multilayers. In addition, to investigate the effect of annealing on physical properties of deposited $\mathrm{AgGaSe}_{2}$ thin films, the postannealing in the temperature range of $300-550^{\circ} \mathrm{C}$ was employed, which was carried out on a hot plate under $\mathrm{N}_{2}$ gas flow for $30 \mathrm{~min}$. After optimization stages of thin film, a $\sim 700 \mathrm{~nm}$ thick AGS layer was deposited onto the synthesized $\mathrm{ZnO} \mathrm{NWs}$ for the realization of SLG/ITO/n-ZnO NWs/p$\mathrm{AgGaSe}_{2}$ core-shell solar cell. For the top and bottom contacts of the device, thermally evaporated indium dot contacts (using a dot-patterned copper mask) and SLG precoated with ITO were employed, respectively.

To determine the structural, electrical, and optical properties of deposited AGS thin films several characterization techniques have been applied. The crystal structure and orientation, existing material phases, and the size of the grains 


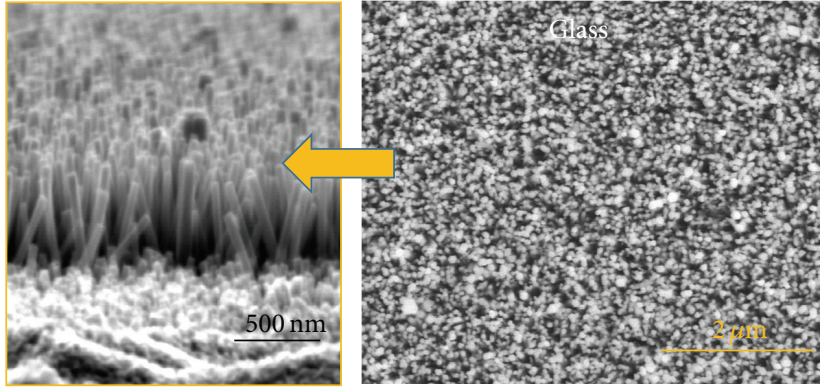

(a)

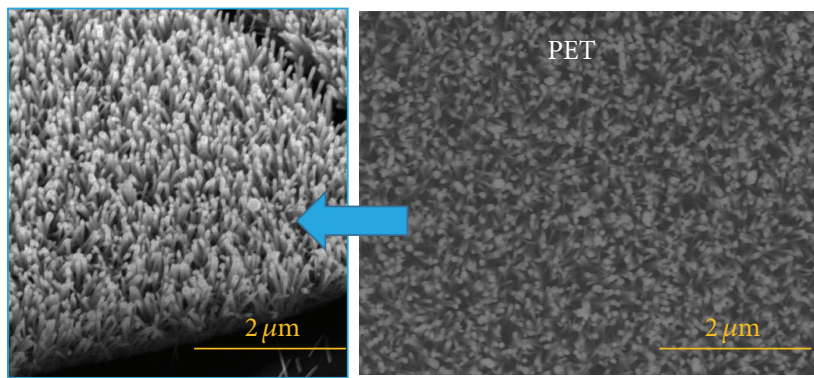

(c)
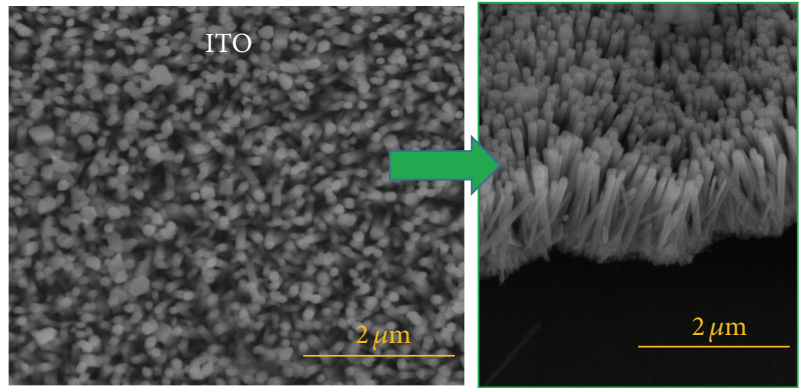

(b)
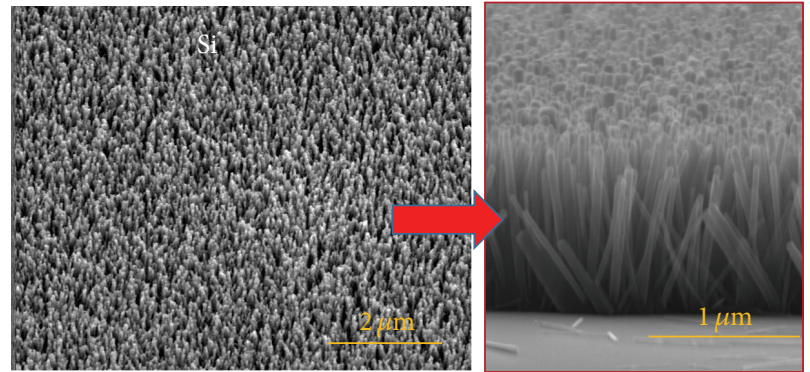

(d)

Figure 1: Top-view and tilted-view SEM images of ZnO nanowires grown on (a) soda-lime glass, (b) indium tin oxide, (c) polyethylene terephthalate (PET), and (d) Silicon (Si) by using hydrothermal technique.

were determined by means of X-ray diffraction (XRD) using a Scintag XDS2000 powder X-ray diffractometer with $\mathrm{CuK}_{\alpha}$ radiation source. The optical properties were investigated by performing transmission measurements in the wavelength range of $300-1100 \mathrm{~nm}$ using an Ocean Optics UVVIS spectrometer. Electrical measurements were carried out using a four-point van der Pauw method. Ohmic contacts on chalcopyrite thin films (AGS) were achieved by thermal evaporation of high pure In using a convenient copper mask. For the electrical characterization of AGS thin films, following the confirmation of ohmic nature of contacts, temperature dependent conductivity and photoconductivity measurements were carried out in temperature range of 100$430 \mathrm{~K}$ in a Janis cryostat equipped with Keithley's 220 current source, Keithley's 619 electrometer, Keithley's 2400 digital SourceMeter and a Lake shore 331 temperature controller. The surface morphology, composition, and thickness of deposited thin films as well as the morphology of $\mathrm{ZnO}$ NWs were determined by a Hitachi S-4100 FE scanning electron microscopy (SEM) equipped with EDXA. The current-voltage $(I-V)$ characteristic of fabricated solar cell was measured at room temperature $(300 \mathrm{~K})$ using a LabVIEW controlled Keithley's 2400 SourceMeter. Finally, testing of fabricated solar cells was performed in Oriel $1000 \mathrm{~W}$ solar cell simulator setup (under AM 1.5 conditions), which was controlled with Newport $I-V$ test software.

\section{Results and Discussion}

Figure 1 shows typical scanning electron microscope (SEM) image of $\mathrm{ZnO}$ nanowires (NWs) grown on different substrates including silicon ( $\mathrm{Si}$ ), soda-lime glass (SLG), indium tin oxide (ITO) precoated SLG, and polyethylene terephthalate (PET) by using hydrothermal technique. ZnO NWs were grown on the aforementioned substrates precoated with $\sim 30 \mathrm{~nm}$ thick $\mathrm{ZnO}$ seed layer deposited by RF sputtering. Growth time and temperature were chosen as $3 \mathrm{~h}$ and $90^{\circ} \mathrm{C}$, respectively.

From the images presented in Figure 1, it is apparent that $\mathrm{ZnO} N W s$ are $1.2-1.3 \mu \mathrm{m}$ long and $65-95 \mathrm{~nm}$ in diameter, which are nearly uniformly distributed over the surface of the substrates. In addition, it can be seen from the images that highly dense and vertically well-oriented $\mathrm{ZnO} N W$ s can be grown on any substrates as long as they can withstand growth temperature $\left(\sim 90^{\circ} \mathrm{C}\right)$ and chemical used in the precursor solution required for growth of NWs by hydrothermal approach. In particular, the growth of $\mathrm{ZnO}$ NWs on a flexible substrate such as PET is very important since it allows the realization of flexible optoelectronic devices including UV photodetectors, solar cells, and light emitting diodes (LEDs).

In order to reveal the effect of growth time on diameter of $\mathrm{ZnO} \mathrm{NWs}$, grown on sputter-deposited $\mathrm{ZnO}$ seed layer with thickness of $\sim 30 \mathrm{~nm}$ onto SLG substrates, growth was carried out for $1.5 \mathrm{~h}$ and $3 \mathrm{~h}$ time duration by keeping the other growth parameters constant. As can be seen from SEM images illustrated in Figure 2, there is a significant difference between the diameters of grown $\mathrm{ZnO}$ NWs for these growth time durations, which are $\sim 60 \mathrm{~nm}$ and $\sim 90 \mathrm{~nm}$ for $1.5 \mathrm{~h}$ and $3 \mathrm{~h}$, respectively. The present findings on the relation between growth time and nanowire diameter seem to be consistent with other findings of a great deal of the previous works focused on this correlation. The observed increase in diameter with increasing growth time is generally attributed to the coalescence of poor-oriented longer NWs. 


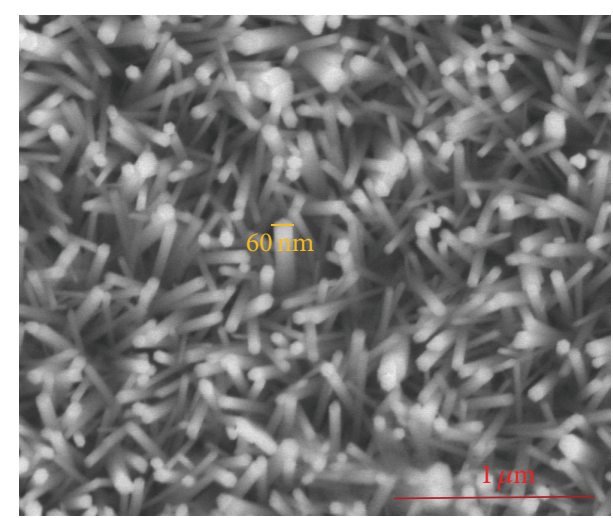

(a)

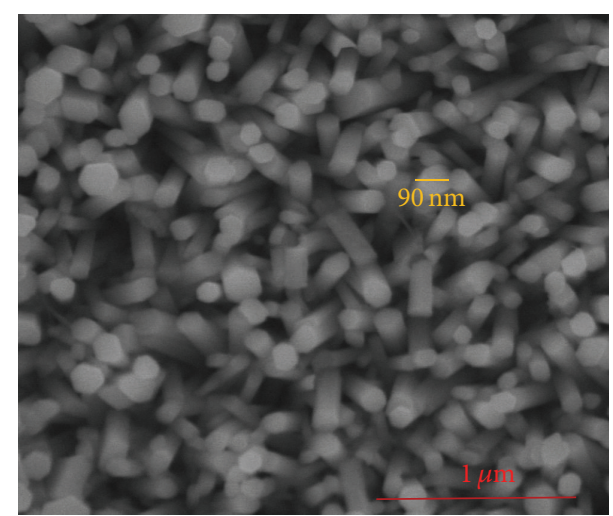

(b)

FIGURE 2: Top-view SEM images of $\mathrm{ZnO}$ nanowires grown on soda-lime glass substrates for growth times of (a) $1.5 \mathrm{~h}$ and (b) $3 \mathrm{~h}$.

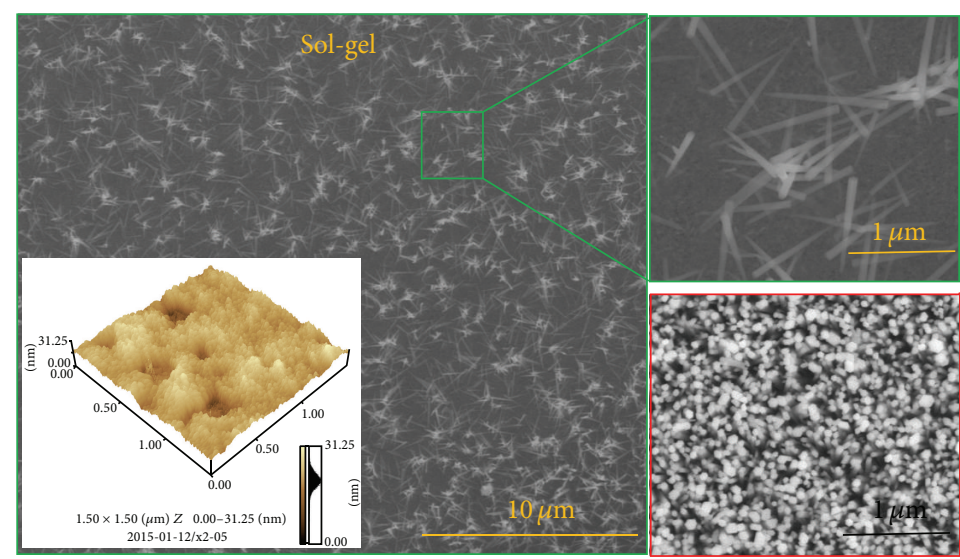

(a)

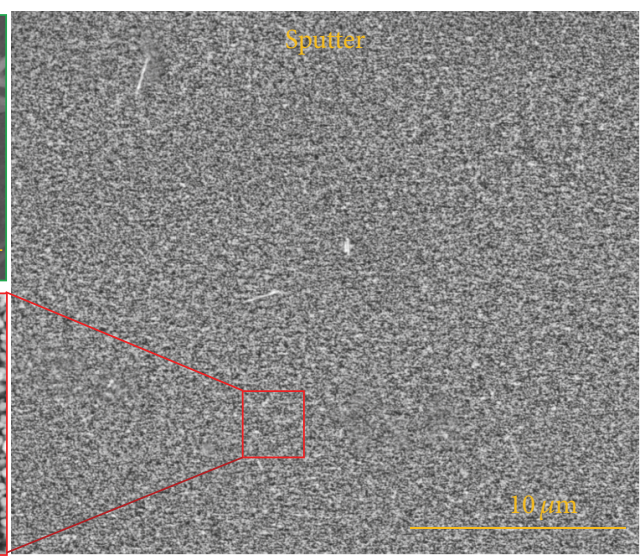

(b)

Figure 3: Top-view SEM images of $\mathrm{ZnO}$ nanowires synthesized on $\mathrm{ZnO}$ seed layers (on soda-lime glass substrates (SLG)) deposited by (a) sol-gel and (b) sputtering techniques. Inset figure shown in part (a) presents the AFM image recorded for ZnO seed layer on SLG substrate deposited by sol-gel route.

It is possible, therefore, that, by using the revealed correlation between these two parameters, the aspect ratio of $\mathrm{ZnO} \mathrm{NWs}$ can be adjusted for specific device applications, such as light scattering, guiding, and trapping to enhance the absorption of incident light for photovoltaic applications.

In addition to the effect of growth time, the effect of seed layer deposition route on the morphology of $\mathrm{ZnO}$ NWs has been determined by comparing the quality of NWs grown on $\mathrm{ZnO}$ seed layers deposited by sol-gel and sputtering techniques, SEM images of which are presented in Figure 3. During the NW growth stage all the growth parameters including temperature, precursor concentration, and orientation of substrate with respect to the wall of beaker and growth time except seed layer deposition approach were kept constant to reveal the effect of this parameter. As can be seen in Figure 3, there is a significant difference between the quality of NWs grown on seed layers deposited by different routes in terms of density, orientation, and uniformity of synthesized NWs. The obtained results suggest that seed layer deposition route has a strong impact on NW quality and the best quality comes with NWs grown on sputter-deposited $\mathrm{ZnO}$ seed layer.

In other words, it was observed that well-oriented, homogenously distributed dense arrays of $\mathrm{ZnO}$ NWs were synthesized on sputter-deposited $\mathrm{ZnO}$ seed layer, which was not the case for the NWs grown on sol-gel deposited one. To understand the origin of this difference, the atomic force microscope (AFM) measurement was conducted for the $\mathrm{ZnO}$ seed layer deposited by sol-gel, image of which is given as inset in Figure 3(a). It is clear from this image that the surface of the deposited seed layer is not uniform and consisted of well-like features that randomly distributed over the surface. As expected, it is not possible to deposit very uniform continuous $\mathrm{ZnO}$ thin film layers by sol-gel as opposed to sputtered layers, which promotes the formation of these features. Among the plausible explanation for the observed low quality of ZnO NWs grown on sol-gel deposited seed layer, in terms of orientation, density, and uniformity, we can suggest that it is these well-like features which trigger the formation of poor-oriented low quality NWs. In other words, 


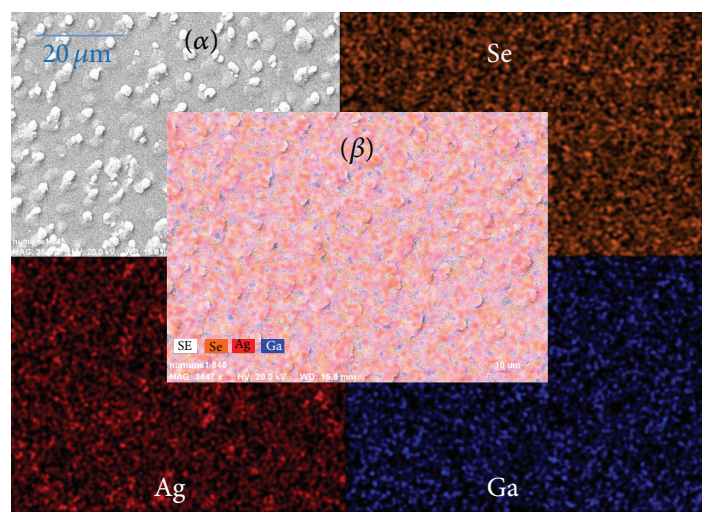

(a)

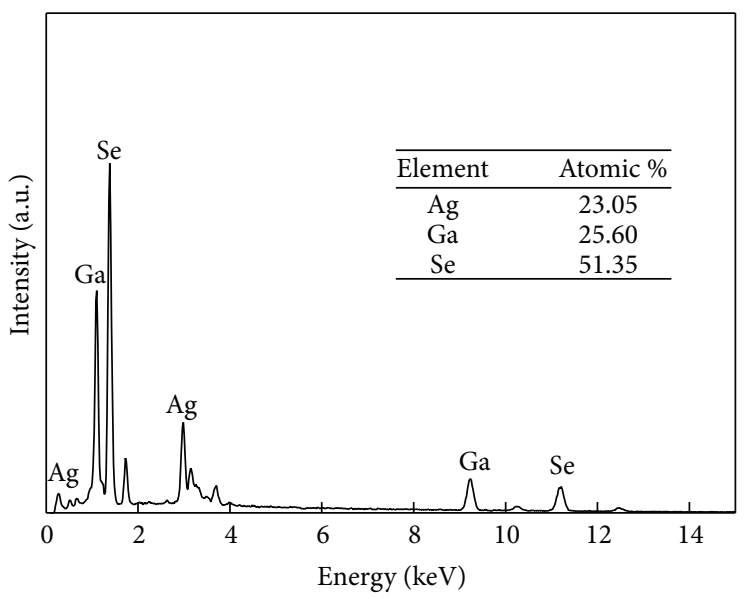

(b)

FIGURE 4: (a) SEM images showing the elemental mapping for the constituent element of as-grown AgGaSe ${ }_{2}$ thin film: uncolored image at left top shows the bare surface of thin film before the elemental mapping; the one at the center shows combined elemental mapping. (b) EDXA pattern and calculated atomic percentage of constitute elements in as-grown $\mathrm{AgGaSe}_{2}$ thin film deposited onto soda-lime glass substrate.

these randomly distributed features may function as seeding centers that promote the formation of $\mathrm{ZnO} \mathrm{NW}$ nucleations, from which NWs derive. It is, therefore, expected that the shape and density of these features will be the two important factors that will assign the quality of synthesized $\mathrm{ZnO}$ NWs.

To investigate the stoichiometry of deposited $\mathrm{AgGaSe}_{2}$ thin films, energy dispersive X-ray analysis (EDXA) measurements were performed at $20 \mathrm{keV}$ for as-grown sample. The EDXA pattern and atomic percentage of constituent elements are given in Figure 4. As expected, all constitute elements appeared in the spectrum at specific energy values (Figure 4(b)). Based on the measured values of atomic percentage of elements, it is possible to claim that a nearly stoichiometric $\mathrm{AgGaSe}_{2}$ thin film (inside the interval of experimental error limit (1-2\%)) is successfully obtained.

Beside the EDAX pattern, as shown in Figure 4(a), we have obtained elemental mapping for constitute elements for as-grown thin film to determine the distribution of elements in the sequential layers of deposited $\mathrm{AgGaSe}_{2}$ thin film. It is clear from the map that Se and Ag elements cover the majority part of surface, while Ga is just beneath them, which implies the existence of uncompleted reaction for the construction of an ordered $\mathrm{AgGaSe}_{2}$ structure, possibly due to insufficient heat energy supplied during deposition process $\left(150^{\circ} \mathrm{C}\right)$.

Figure 5 shows the $\mathrm{X}$-ray diffraction pattern recorded for as-grown film and $\mathrm{AgGaSe}_{2}$ thin film annealed in the temperature range of $300-550^{\circ} \mathrm{C}$. As can be seen from the figure, the as-grown film is polycrystalline and consisted of single phase AgGaSe ${ }_{2}$ having chalcopyrite structure with lattice parameters of $a=b=5.993 \AA$ and $c=10.884 \AA$ [24]. Following the postannealing between 300 and $550^{\circ} \mathrm{C}$, it was observed that the intensity of all peaks which appeared in XRD pattern increases gradually with increase in annealing temperature, which closely related with the improvement in crystallinity. The improvement of crystallinity can be attributed to the elimination of imperfections in structure following the postannealing process at high temperatures.

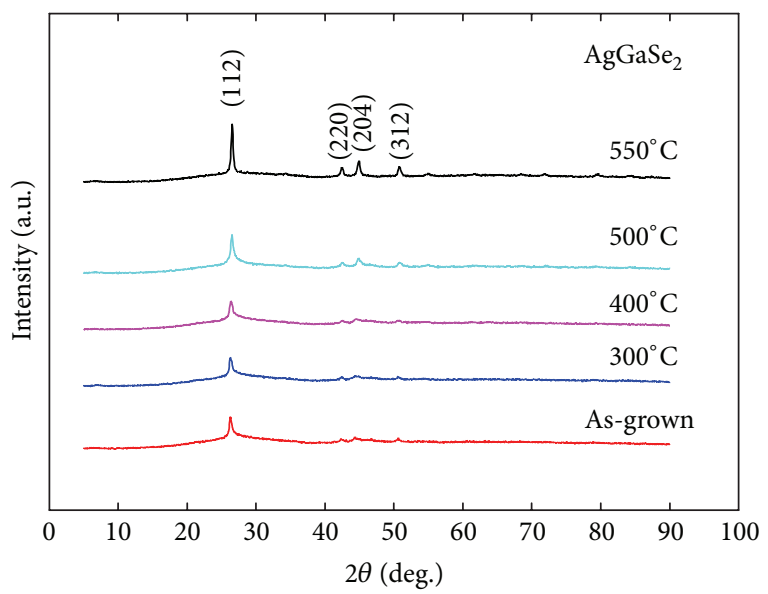

FIGURE 5: X-ray diffraction pattern obtained for as-grown film and $\mathrm{AgGaSe}_{2}$ thin film annealed between 300 and $550^{\circ} \mathrm{C}$.

In our previous studies, although several attempts have been made to deposit single phase AGS at low substrate or annealing temperatures, we could not achieve it due to either appearance of secondary phases such as $\mathrm{Ag}$ or the requirement of deposition of this material on substrates that can withstand high annealing temperature $\left(>550^{\circ} \mathrm{C}\right)$. But here with this study we report the achievement of producing a single phase AGS at quite low substrate temperature $\left(150^{\circ} \mathrm{C}\right)$. Obtaining a thin film in a single phase without any secondary phases is essential for a precise control on optoelectronic devices such as solar cells.

The optical transmittance of deposited and $\mathrm{AgGaSe}_{2}$ thin films has been determined in the wavelength range of $325-1100 \mathrm{~nm}$. The obtained spectra for as-grown film and film annealed between 400 and $550^{\circ} \mathrm{C}$ are presented in Figure 6(a). It can be seen from the transmission spectra that the postannealing process has a remarkable effect on transmittance of AGS thin films. 


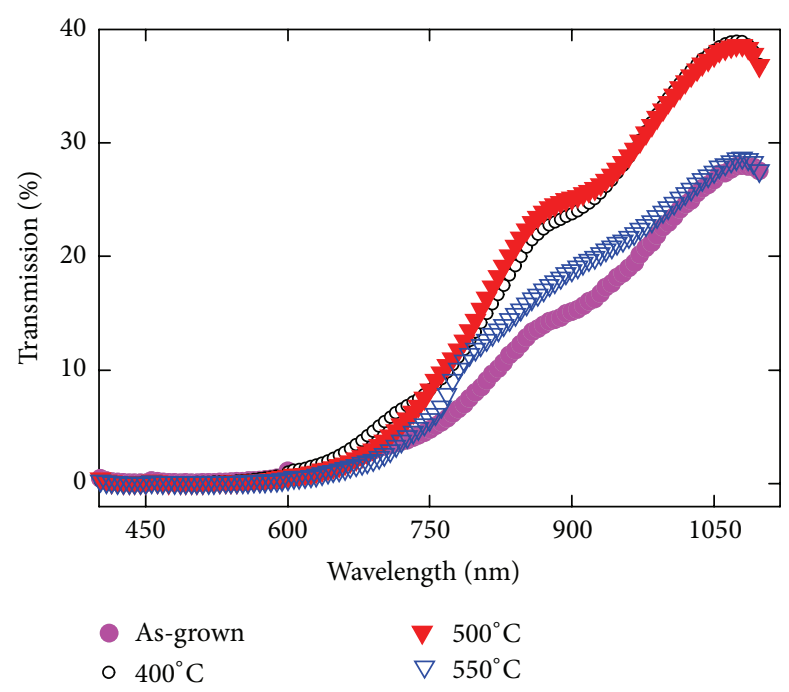

(a)

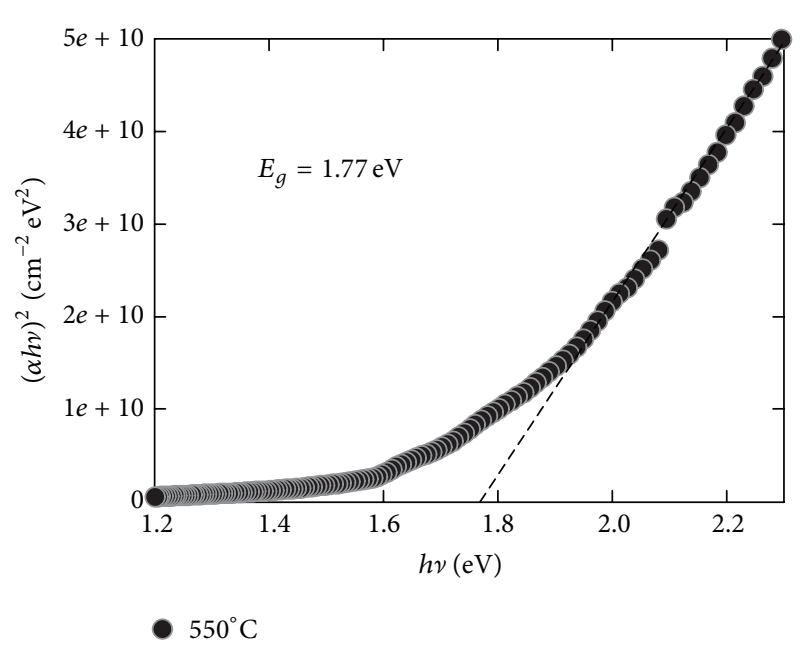

(b)

Figure 6: (a) Transmittance spectra obtained for as-grown film and AgGaSe $e_{2}$ thin film annealed at different temperatures (400, 500, and $550^{\circ} \mathrm{C}$ ) and (b) absorption coefficient $(\alpha)$ and photon energy $(h \nu)$ relation for AGS thin film annealed at $550^{\circ} \mathrm{C}$.

That is, it was observed that there is a systematic increase in transparency with increasing annealing temperature, except for the annealing temperature of $550^{\circ} \mathrm{C}$. The observed increase in transparency may be due to the structural modifications deduced from XRD study in which an improvement in crystallinity was deduced after postannealing process. In other words, postannealing process may end up with reducing defects in polycrystalline structure by which a better crystallinity and homogeneity provided. This may subsequently result in less scattering of light and enhancement in transparency. The optic bandgap $\left(E_{g}\right)$ and absorption coefficient $(\alpha)$ of the deposited films were calculated through transmission spectra presented in Figure 6(a). The relation between absorption coefficient and photon energy $(h \nu)$ for the film annealed at $550^{\circ} \mathrm{C}$ is shown in Figure 6(b). From this relation, the optic bandgap can be determined through the extrapolation of its linear portion of plot to zero absorption coefficient. The bandgap was found to be around $1.77 \mathrm{eV}$, which is in a close agreement with reported values in literature [12].

The temperature dependent conductivity measurements were carried out in the temperature range of $100-430 \mathrm{~K}$ for as-grown film and films annealed between 400 and $550^{\circ} \mathrm{C}$. The variation of conductivity as a function of temperature is shown in Figure 7(a).

It can be seen from Figure 7(a) that the conductivity increases as the temperature increases. As mentioned before, this behavior verifies that AGS thin films are acting as semiconductor material. The type of conduction was determined by hot probe method, which revealed that it was a p-type character. Obtaining a p-type AGS thin film was an essential requirement for this study to construct a $\mathrm{p}$ $\mathrm{n}$ heterojunction with $\mathrm{n}$-type $\mathrm{ZnO}$ nanowires. It can also be seen from Figure 7(a) that the conductivity decreases following the postannealing process. The room temperature resistivity values were found to be around $5.3 \times 10^{2}, 5.5 \times 10^{5}$, and $2.6 \times 10^{5}(\Omega \cdot \mathrm{cm})$ for as-grown film and sample annealed at 500 and $550^{\circ} \mathrm{C}$, respectively. The increase in resistivity of the annealed film with respect to the as-grown one may stem from the unreacted sequentially deposited single layers of $\mathrm{Ag}$ and $\mathrm{GaSe}$ at low substrate temperature $\left(150^{\circ} \mathrm{C}\right)$. Therefore, in as-grown polycrystalline structure there may be unreacted Ag agglomerations that have possibility to act as conductive path for the transport of free charge carriers. However, it is not the case for the annealed samples due to the existence of ordered structure of $\mathrm{AgGaSe}_{2}$, which is a semi-insulating material, following the postannealing process. This result is in line with data extracted from XRD study by which the improvement of crystallinity of $\mathrm{AgGaSe}_{2}$ phase has been deduced. In addition, as can be seen from Figure 7(a), the observed behavior of conductivity follows the Arrhenius relation [25]:

$$
\sigma=\sigma_{o} \exp \left[-\frac{E_{a}}{k T}\right]
$$

where $\sigma_{o}, E_{a}$, and $k$ are preexponential factor, activation energy, and Boltzmann's constant, respectively. Here, $E_{a}$ is the activation energy corresponding to a specific current mechanism activated at a specific temperature interval. $\operatorname{Ln}(\sigma)$ versus $1000 / T$ plot reveals two distinct linear regions for all samples, implying existence of two different local states with different activation energies, which is activated at low and high temperature intervals. Since the type of conduction was found as p-type, it can thus be suggested that these states are associated with acceptor levels, formation of which is triggered as a consequence of a small deviation from stoichiometry deduced from the EDAX study. It is known that this deviation may result in the generation of group-VI (Se) vacancies that act as acceptors in chalcopyrite structures. 


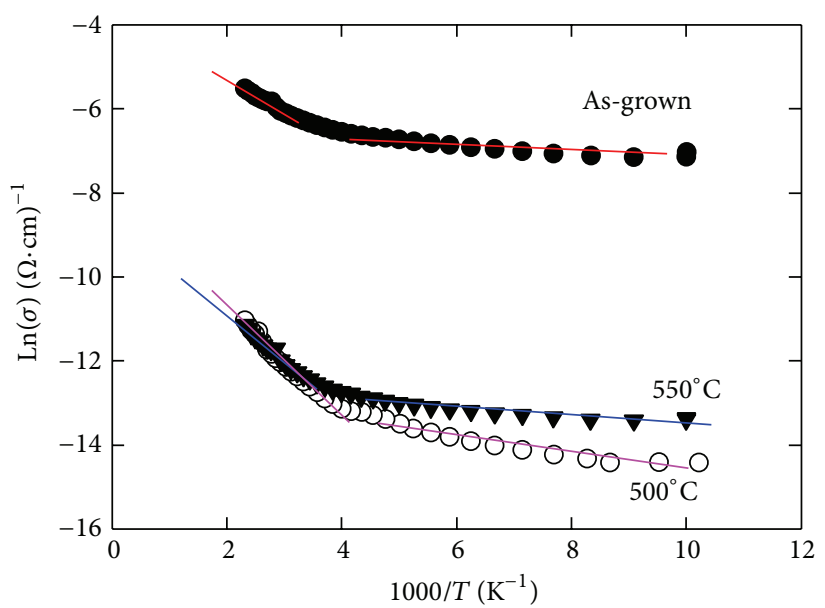

(a)

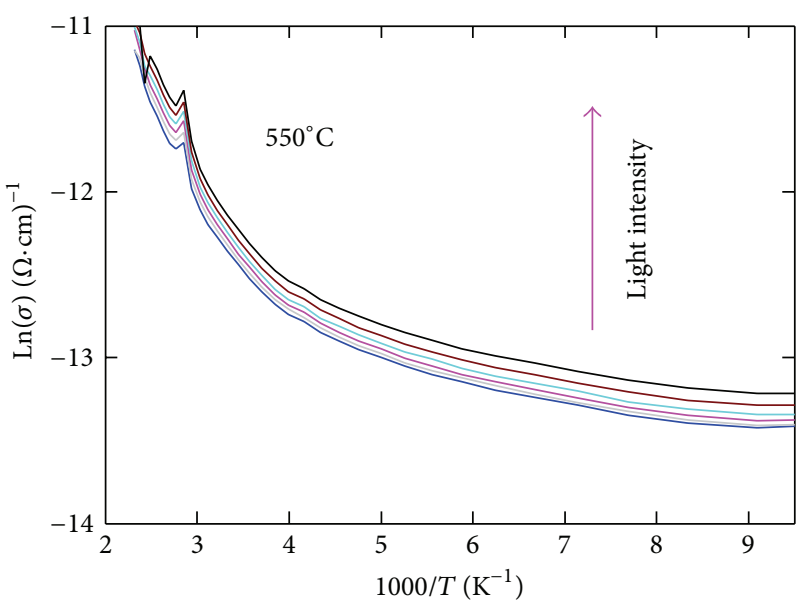

(b)

Figure 7: (a) The variation of conductivity as a function of temperature for as-grown film and $\mathrm{AgGaSe}_{2}$ thin film annealed at 500 and $550^{\circ} \mathrm{C}$. (b) Temperature dependent conductivity of $\mathrm{AgGaSe}_{2}$ thin film annealed at $550^{\circ} \mathrm{C}$ under different illumination intensities (between 20 and $\left.115 \mathrm{~mW} / \mathrm{cm}^{2}\right)$.

In addition to dark conductivities, the temperature dependent conductivities under different illumination intensities (provided by a halogen lamp (from 20 to $115 \mathrm{~mW} / \mathrm{cm}^{2}$ )) have also been measured in the temperature range of 100$430 \mathrm{~K}$. The variation for the film annealed at $550^{\circ} \mathrm{C}$ is shown in Figure 7(b). It can be seen from this variation that the conductivity increases linearly almost at the same increments with increasing light intensity from 20 to $115 \mathrm{~mW} / \mathrm{cm}^{2}$, which verifies the existence of photoresponse for this material under light, and it can be employed as an absorber layer in the photovoltaic device structure.

Figure 8(a) Shows SEM image of the structure of a fully fabricated $\mathrm{n}-\mathrm{ZnO} \mathrm{NWs} / \mathrm{p}-\mathrm{AgGaSe}{ }_{2}$ core-shell solar cell. It is apparent from the image that $\mathrm{ZnO} \mathrm{NWs}$ are decorated with sputtered $\mathrm{AgGaSe}_{2}$ layer for the realization of $\mathrm{p}-\mathrm{n}$ heterojunction solar cell. It is also clear that the AGS layer at the top part of $\mathrm{ZnO}$ NWs is thicker than that at the bottom part, which can be attributed to the limitation of our technique, sputtering, for the decoration of AGS layer [26]. In other words, $\mathrm{ZnO}$ NWs are not conformally coated with AGS layer and are thicker than desired. Therefore, $\mathrm{ZnO}$ NWs in the completed solar cell structure are connected by the pAGS canopy layer (a continuous film), resulting in a planer surface of a hybrid thin film nanowire structured device. For a core-shell structured solar cell, although it is reasonable to expect enhanced carrier collection efficiency, it is not the case for optical properties, which are almost similar to thin film or wafer-based solar cell architecture owing to its planer top surface [27]. As the fabricated device is the first prototype, there are many issues we must address. The surface morphology is among them. Our ongoing work has focused on adjusting the shell layer's thickness for the realization of conformally coated $\mathrm{ZnO}$ NWs, which are desired for the more incident light absorption through light trapping and scattering.

Figure 8 (b) presents the current-voltage $(I-V)$ characteristic of the fabricated solar cell obtained under dark condition. As can be seen from the $I-V$ curve, there is a good rectification (forward-current/reverse-current $=8$ at $1 \mathrm{~V}$ ), which verifies the construction of $\mathrm{p}-\mathrm{n}$ heterojunction between $\mathrm{ZnO} \mathrm{NWs}$ as core component and AGS as shell component. In order to determine the performance of constructed prototype core-shell solar cell, the $I-V$ measurement was also carried out under light illumination (AM 1.5, $100 \mathrm{~mW} / \mathrm{cm}^{2}$ ). The $I-V$ characteristic of $\mathrm{n}-\mathrm{ZnO} \mathrm{NWs} / \mathrm{p}-$ $\mathrm{AgGaSe}_{2}$ solar cell with a contact area of $0.06 \mathrm{~cm}^{2}$ measured with a solar simulator under standard AM 1.5 condition is shown in Figure 8(c). Solar parameters such as open-circuit voltage $\left(V_{\text {oc }}\right)$, short circuit current density $\left(J_{\mathrm{sc}}\right)$, fill factor $(\mathrm{FF})$, and power conversion efficiency $(\eta)$ were calculated from the $I-V$ curve obtained under light illumination with respective $0.098 \mathrm{~V}, 29.40 \mathrm{~mA} / \mathrm{cm}^{2}, 60.25 \%$, and $1.74 \%$ values. There are only a few studies in literature that deal with coreshell solar cells based on integration of NWs into chalcopyrite thin films. For instance, energy efficiencies for core-shell solar cells consisted of $\mathrm{ZnO} / \mathrm{CdS} / \mathrm{CIGS}$ and $\mathrm{ZnO} /(\mathrm{Zn}, \mathrm{Mg}) \mathrm{O} / \mathrm{CIGS}$ were found to be as $2.18 \%$ and $4.1 \%$, respectively [28]. However, in the present investigation, as it is the first study based on reporting the performance of core-shell $\mathrm{n}-\mathrm{ZnO}$ $\mathrm{NWs} / \mathrm{p}-\mathrm{AgGaSe} e_{2}$ solar cell, it is not possible to compare the results with that reported in literature. In addition, when compared with its $\mathrm{AgGaSe}_{2}$ based planer counterparts (with power conversion efficiencies of $4.5-7.8 \%$ ), there is no doubt that it has a lower power conversion efficiency that may stem from several potential factors including the quality of AGS thin film, unoptimized geometry of $\mathrm{ZnO}$ NWs, high resistivity of $\mathrm{ZnO}$ material, and some contact issues $[29,30]$. In particular, it is observed that there is low $V_{\text {oc }}$ associated with the constructed core-shell solar cell. The open-circuit voltage $\left(V_{\mathrm{oc}}\right)$ of the $\mathrm{p}-\mathrm{n}$ junction solar cell is given by the following relation:

$$
V_{\mathrm{oc}}=\frac{n k T}{q} \operatorname{Ln}\left(\frac{J_{\mathrm{sc}}}{J_{o}}+1\right)
$$




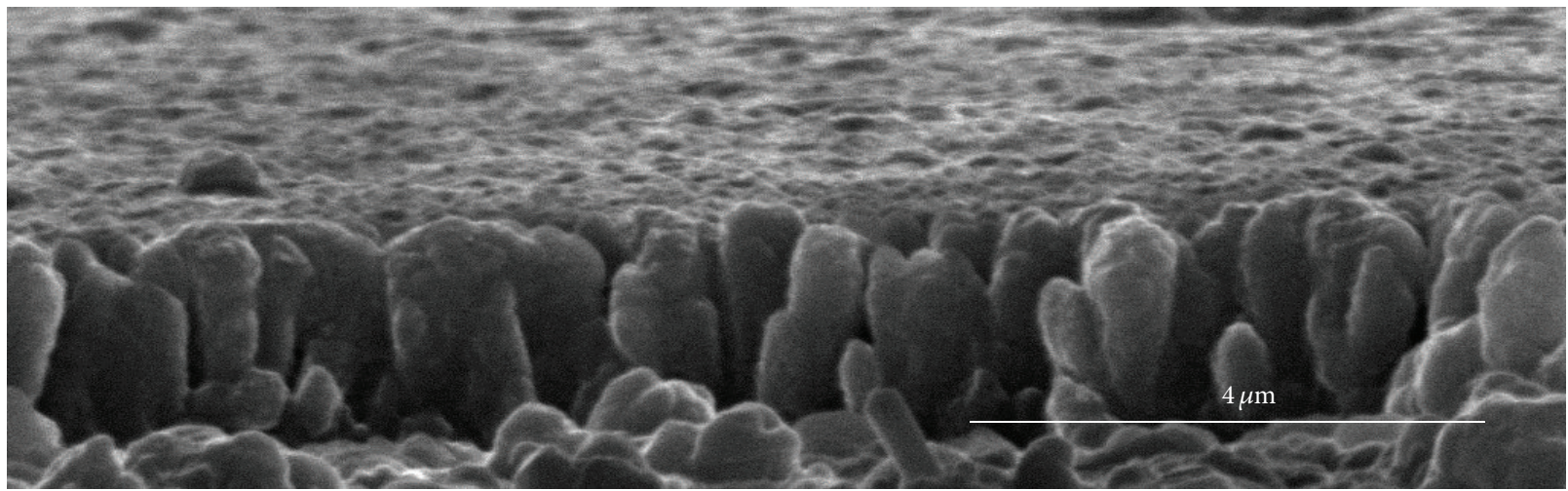

(a)

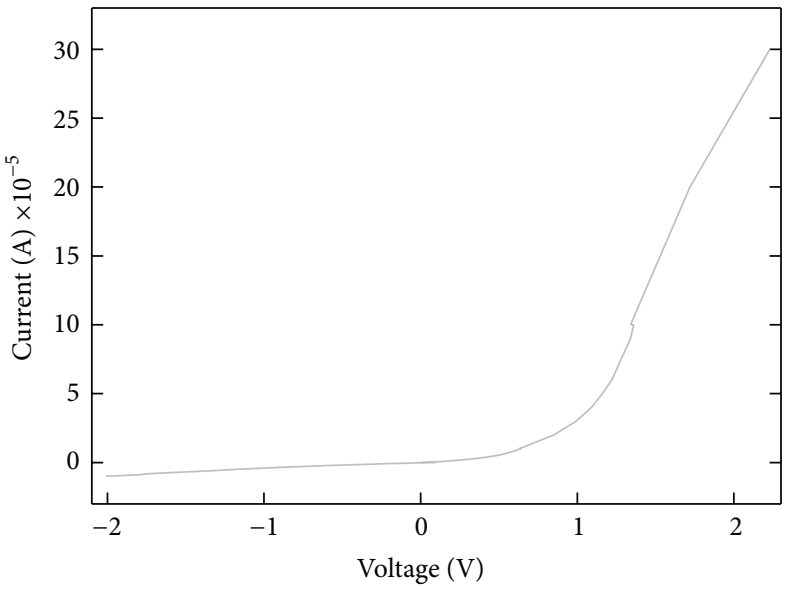

(b)

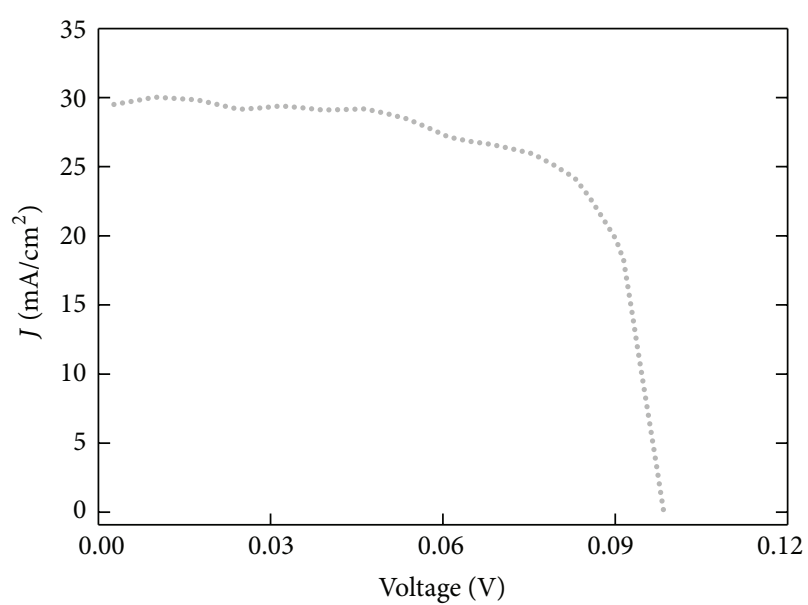

(c)

FIGURE 8: (a) Cross-sectional view of SEM image of the structure of a fully fabricated n-ZnO NWs/p-AgGaSe $e_{2}$ core-shell solar cell. (b) Current-voltage $(I-V)$ characteristic of the fabricated solar cell recorded under dark condition and (c) under $100 \mathrm{~mW} / \mathrm{cm}^{2}$ of simulated solar illumination.

where $J_{\text {sc }}$ and $J_{o}$ are short-circuit current density and saturation current density, respectively. From this relation, it is evident that, to get large $V_{\text {oc }}, J_{o}$ should be small. Since the saturation current density is inversely proportional to the minority carrier life time, to decrease it the minority carrier life time should be long [31]. It is a well-known fact that onedimensional nanostructures based solar cell architectures offer a high surface/volume ratio, which give rise to the formation of surface defects, traps in depletion region, and dangling bonds. These surface defects promote the surface recombination of photo-generated minority carriers and are resulting in short minority carrier life times. Therefore, the observed low $V_{\text {oc }}$ can be attributed to the short minority carrier life (high saturation current density) due to the high recombination rate in the core-shell device structure [32]. A considerable amount of similar results has been reported in literature for core-shell solar cells [1,32-35]. These studies showed that although these architectures provide promising short current densities, it was not the case for open-circuit voltages, which was either attributed to shunt path stemming from nonuniform core-shell structure or short minority carrier life time resulting from high recombination rate due to the large surface/volume ratio. It can thus be suggested that the careful synthesis of a nanostructured $p-n$ junction is playing a critical role in determining the open-circuit voltage that can be extracted from a core-shell architecture solar cell. Moreover, it can be expected that more efficient coreshell $\mathrm{n}-\mathrm{ZnO} \mathrm{NWs} / \mathrm{p}-\mathrm{AgGaSe}_{2}$ solar cells can be realized by producing $\mathrm{ZnO}$ NWs by consideration of right aspect ratio and density for efficient light absorption, low-resistive $\mathrm{ZnO}$ and AGS thin films, and formation of high quality ohmic contacts.

\section{Conclusions}

Dense arrays of $\mathrm{ZnO}$ nanowires (NWs) were successfully synthesized on different substrates such as silicon, sodalime glass (SLG), indium tin oxide (ITO), and polyethylene terephthalate (PET) by employing hydrothermal technique. In particular, the growth of $\mathrm{ZnO} \mathrm{NWs}$ on a flexible substrate such as PET is very important since it would allow the realization of flexible optoelectronic devices including photodetectors, solar cells, and light emitting diodes. During the nanowire growth cycle, it was found that there was 
an important correlation between growth time and the diameter of NWs; in other words, there was an increase in diameter with increasing growth time, which was attributed to the coalescence of poor-aligned NWs at longer times. In addition to this, results revealed that there was a strong impact of the deposition routes of $\mathrm{ZnO}$ seed layer, which were sol-gel and sputtering, on quality of synthesized $\mathrm{ZnO}$ NWs in terms of orientation with respect to the normal of the substrate, diameter, homogeneity in length, uniformity, and density of nanowires.

As an application of synthesized $\mathrm{ZnO}$ NWs, a coreshell type solar cell based on $n-\mathrm{ZnO}$ NWs/p-AgGaSe 2 (AGS) materials combination was fabricated. Prior to realization of the device structure, AGS thin films were deposited on SLG substrates via sputtering technique and then structural, electrical, and optical properties were investigated in detail. Once the best quality AGS thin film was obtained, $\mathrm{ZnO}$ NWs were decorated with it for the construction of a core-shell structured solar cell. From the measurement under $100 \mathrm{~mW} / \mathrm{cm}^{2}$ of simulated solar illumination, the open-circuit voltage, short circuit current density, fill factor, and energy conversion efficiency were found to be $0.098 \mathrm{~V}, 29.40 \mathrm{~mA} / \mathrm{cm}^{2}, 60.25 \%$, and $1.74 \%$ respectively, which could be taken as encouraging results for next generation nanowire based solar cells and will serve as a base for future studies.

\section{Conflict of Interests}

The authors declare that there is no conflict of interests regarding the publication of this paper.

\section{Acknowledgment}

This work was supported by Turkish Scientific and Research Council (TUBITAK) under Grant no 114F251.

\section{References}

[1] J. A. Czaban, D. A. Thompson, and R. R. LaPierre, "GaAs coreshell nanowires for photovoltaic applications," Nano Letters, vol. 9, no. 1, pp. 148-154, 2009.

[2] Z. Fan, D. J. Ruebusch, A. A. Rathore et al., "Challenges and prospects of nanopillar-based solar cells," Nano Research, vol. 2, no. 11, pp. 829-843, 2009.

[3] X. Zhang, L. S. Wang, and G. Y. Zhou, "Synthesis of wellaligned $\mathrm{ZnO}$ nanowires without catalysts," Reviews on Advanced Materials Science, vol. 10, no. 1, pp. 69-72, 2005.

[4] G. Divitini, N. O. V. Plank, H. J. Snaith, M. E. Welland, and C. E. Ducati, "High-resolution TEM characterization of $\mathrm{ZnO}$ coreshell nanowires for dye-sensitized solar cells," Journal of Physics: Conference Series, vol. 241, no. 1, Article ID 012031, 2010.

[5] M. Law, L. E. Greene, A. Radenovic, T. Kuykendall, J. Liphardt, and P. Yang, " $\mathrm{ZnO}-\mathrm{Al}_{2} \mathrm{O}_{3}$ and $\mathrm{ZnO}-\mathrm{TiO}_{2}$ core-shell nanowire dye-sensitized solar cells," Journal of Physical Chemistry B, vol. 110, no. 45, pp. 22652-22663, 2006.

[6] N. O. V. Plank, H. J. Snaith, C. Ducati, J. S. Bendall, L. SchmidtMende, and M. E. Welland, "A simple low temperature synthesis route for $\mathrm{ZnO}-\mathrm{MgO}$ core-shell nanowires," Nanotechnology, vol. 19, no. 46, Article ID 465603, 2008.
[7] H. Karaagac, M. Kaleli, and M. Parlak, "Characterization of $\mathrm{AgGa}_{0.5} \mathrm{In}_{0.5} \mathrm{Se}_{2}$ thin films deposited by electron-beam technique," Journal of Physics D: Applied Physics, vol. 42, no. 16, Article ID 165413, 2009.

[8] I. Repins, M. A. Contreras, B. Egaas et al., "19.9\%-efficient $\mathrm{ZnO} / \mathrm{CdS} / \mathrm{CuInGaSe} 2$ solar cell with $81.2 \%$ fill factor," Progress in Photovoltaics: Research and Applications, vol. 16, no. 3, pp. 235-239, 2008.

[9] A. Bosio and A. Romeo, Thin Film Solar Cells: Current Status and Future Trends, Nova Science Publishers, 2011.

[10] K. Kuriyama and F. Nakamura, "Electrical transport properties and crystal structure of LiZnAs," Physical Review B, vol. 36, no. 8, pp. 4439-4441, 1987.

[11] H. Karaagac and M. Parlak, "Effects of annealing on structural and morphological properties of e-beam evaporated $\mathrm{AgGaSe}_{2}$ thin films," Applied Surface Science, vol. 255, no. 11, pp. 59996006, 2009.

[12] H. Karaagac and M. Parlak, "Deposition and characterization of layer-by-layer sputtered AgGaSe ${ }_{2}$ thin films," Applied Surface Science, vol. 257, no. 13, pp. 5731-5738, 2011.

[13] U. N. Roy, Y. Cui, R. Hawrami, A. Burger, L. Orona, and J. T. Goldstein, "AgGaSe 2 : a highly photoconductive material," Solid State Communications, vol. 139, no. 10, pp. 527-530, 2006.

[14] P. G. Schunemann, K. L. Schepler, and P. A. Budni, "Nonlinear frequency conversion performance of $\mathrm{AgGaSe}_{2}, \mathrm{ZnGeP}_{2}$, and CdGeAs 2 ," MRS Bulletin, vol. 23, no. 7, pp. 45-49, 1998.

[15] J. L. Shay and J. H. Wernick, "The chalcopyrite structure and crystal growth," in Ternary Chalcopyrite Semiconductors: Growth, Electronic Properties, and Applications, J. L. S. H. Wernick, Ed., chapter 2, pp. 3-78, Pergamon, 1975.

[16] H. Karaagac, M. Parlak, E. Yengel, and M. S. Islam, "Heterojunction solar cells with integrated $\mathrm{Si}$ and $\mathrm{ZnO}$ nanowires and a chalcopyrite thin film," Materials Chemistry and Physics, vol. 140, no. 1, pp. 382-390, 2013.

[17] H. Karaagac, E. Yengel, and M. S. Islam, "Physical properties and heterojunction device demonstration of aluminumdoped $\mathrm{ZnO}$ thin films synthesized at room ambient via sol-gel method," Journal of Alloys and Compounds, vol. 521, pp. 155-162, 2012.

[18] Y. Su, X. P. Zou, X. M. Meng, G. Q. Teng, G. Q. Yang, and X. $\mathrm{M}$. $\mathrm{Lu}$, "ZnO nanorod arrays and nanowires by hydrothermal growth," Advanced Materials Research, vol. 123-125, pp. 811-814, 2010.

[19] H. Wan and H. E. Ruda, "A study of the growth mechanism of CVD-grown ZnO nanowires," Journal of Materials Science: Materials in Electronics, vol. 21, no. 10, pp. 1014-1019, 2010.

[20] H. J. Xu, Y. M. Hou, J. Y. Gao et al., "Regrowth of template ZnO nanowires for the underlying catalyst-free growth mechanism," Crystal Growth and Design, vol. 11, no. 6, pp. 2135-2141, 2011.

[21] D. J. Yuan, R. Guo, Y. G. Wei et al., "Heteroepitaxial patterned growth of vertically aligned and periodically distributed $\mathrm{ZnO}$ nanowires on GaN using laser interference ablation," Advanced Functional Materials, vol. 20, no. 20, pp. 3484-3489, 2010.

[22] L. Vayssieres, "Growth of arrayed nanorods and nanowires of $\mathrm{ZnO}$ from aqueous solutions," Advanced Materials, vol. 15, no. 5, pp. 464-466, 2003.

[23] M. H. Aslan, A. Y. Oral, E. Menşur, A. Gül, and E. Başaran, "Preparation of c-axis-oriented zinc-oxide thin films and the study of their microstructure and optical properties," Solar Energy Materials and Solar Cells, vol. 82, no. 4, pp. 543-552, 2004 . 
[24] Joint Committee on Powder Diffraction Standards (JCPDS) Card No: 31-1240.

[25] D. Patidar, K. S. Rathore, N. S. Saxena, K. Sharma, and T. P. Sharma, "Energy band gap and conductivity measurement of CdSe thin films," Chalcogenide Letters, vol. 5, no. 2, pp. 21-25, 2008.

[26] G. B. Jia, M. Steglich, I. Sill, and F. Falk, "Core-shell heterojunction solar cells on silicon nanowire arrays," Solar Energy Materials and Solar Cells, vol. 96, no. 1, pp. 226-230, 2012.

[27] R. Kapadia, Z. Y. Fan, K. Takei, and A. Javey, "Nanopillar photovoltaics: materials, processes, and devices," Nano Energy, vol. 1, no. 1, pp. 132-144, 2012.

[28] J. C. Armstrong and J. B. Cui, "Three-dimensional structures based on $\mathrm{ZnO} / \mathrm{CdS}$ and $\mathrm{ZnO} /(\mathrm{Zn}, \mathrm{Mg}) \mathrm{O}$ core-shell nanowires embedded in $\mathrm{Cu}(\mathrm{In}, \mathrm{Ga}) \mathrm{S}_{2}$ for solar cell applications," Solar Energy Materials and Solar Cells, vol. 141, pp. 356-363, 2015.

[29] G. H. Chandra, O. M. Hussain, S. Uthanna, and B. S. Naidu, "Characterization of $\mathrm{p}-\mathrm{AgGa}{ }_{0.25} \mathrm{In}_{0.75} \mathrm{Se} 2 / \mathrm{n}-\mathrm{Zn}_{0.35} \mathrm{Cd}_{0.655}$ polycrystalline thin film heterojunctions," Materials Science and Engineering B: Solid-State Materials for Advanced Technology, vol. 86, no. 1, pp. 60-63, 2001.

[30] K. Yamada, N. Hoshino, and T. Nakada, "Crystallographic and electrical properties of wide gap $\mathrm{Ag}\left(\mathrm{In}_{1-x}, \mathrm{Ga}_{x}\right) \mathrm{Se}_{2}$ thin films and solar cells," Science and Technology of Advanced Materials, vol. 7, no. 1, pp. 42-45, 2006.

[31] T. Soga, "Fundamentals of solar cell," in Nanostructured Materials for Solar Energy Conversion, T. Soga, Ed., chapter 1, pp. 3-43, Elsevier, Amsterdam, The Netherlands, 2006.

[32] K. Peng, Y. Xu, Y. Wu, Y. Yan, S.-T. Lee, and J. Zhu, "Aligned single-crystalline Si nanowire arrays for photovoltaic applications," Small, vol. 1, no. 11, pp. 1062-1067, 2005.

[33] E. Garnett and P. D. Yang, "Light trapping in silicon nanowire solar cells," Nano Letters, vol. 10, no. 3, pp. 1082-1087, 2010.

[34] B. M. Kayes, H. A. Atwater, and N. S. Lewis, "Comparison of the device physics principles of planar and radial $p-n$ junction nanorod solar cells," Journal of Applied Physics, vol. 97, no. 11, Article ID 114302, 2005.

[35] K. P. Musselman and L. Schmidt-Mende, "Nanostructured inorganic solar cells," Green, vol. 1, no. 1, pp. 7-27, 2011. 

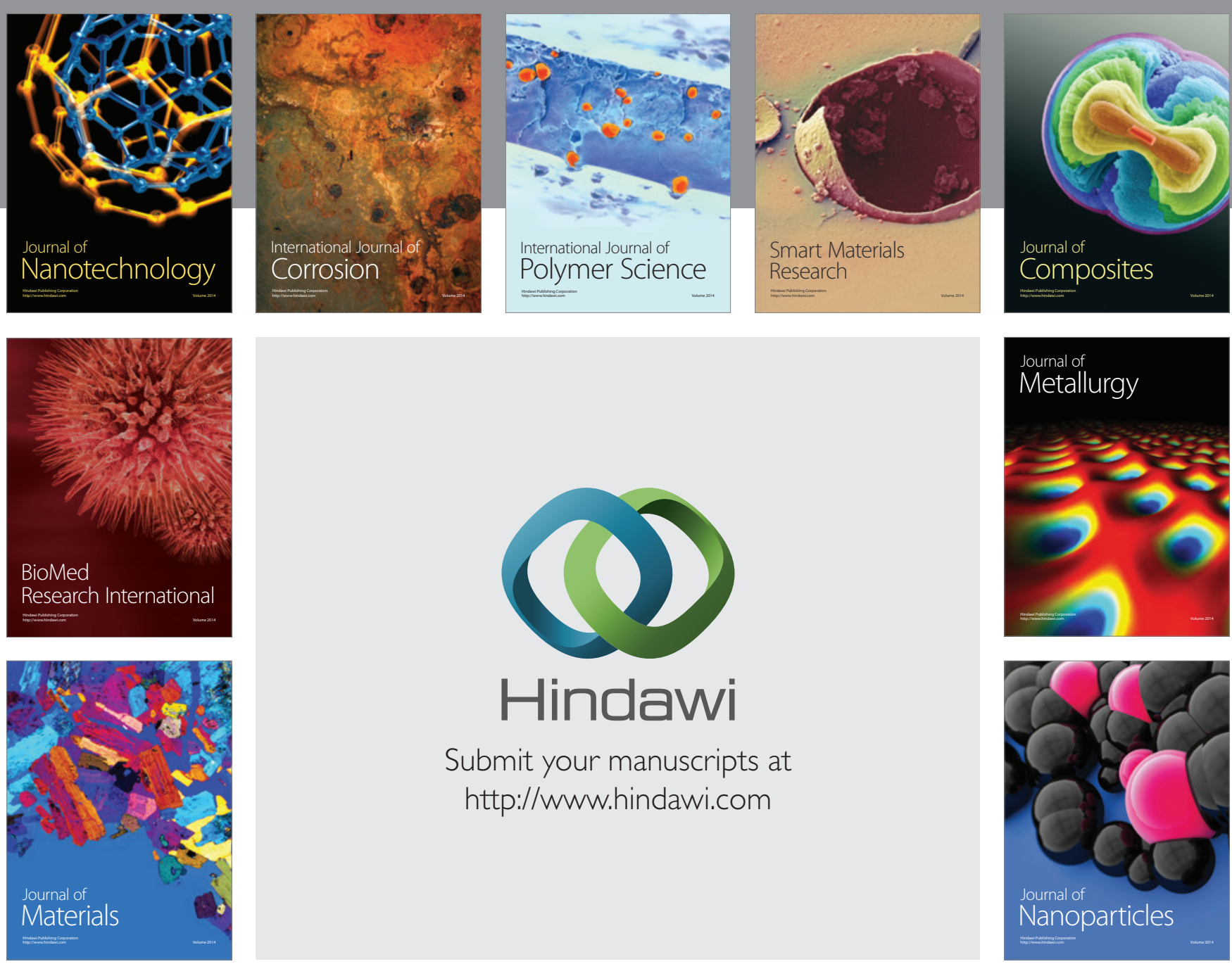

Submit your manuscripts at http://www.hindawi.com
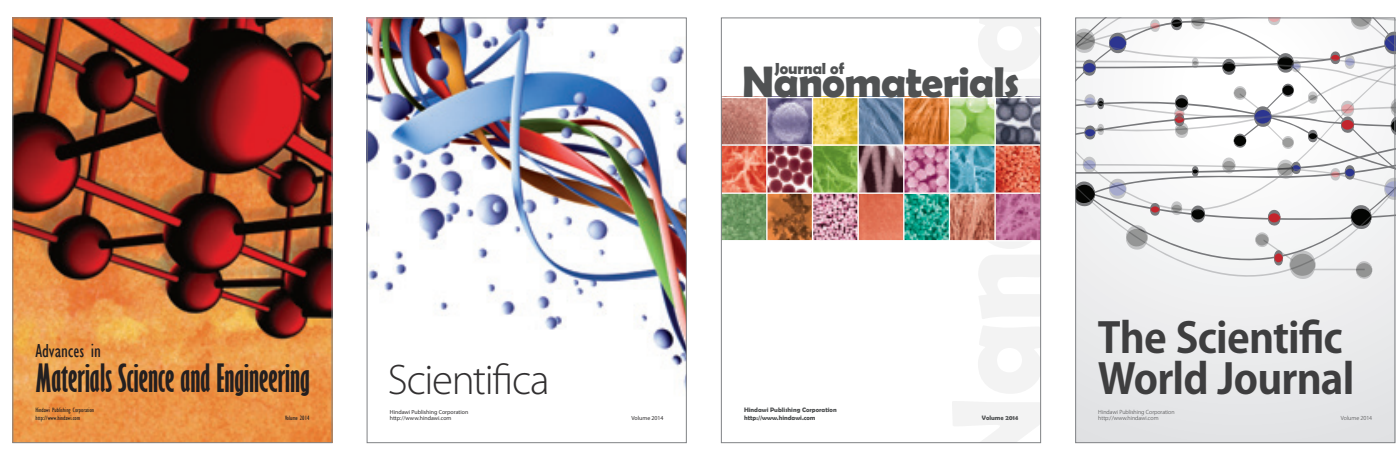

\section{The Scientific World Journal}
